\title{
Methylene blue-mediated photodynamic therapy enhances apoptosis in lung cancer cells
}

\author{
EUN JIN LIM ${ }^{1 *}$, CHUL-HO OAK ${ }^{2,4^{*}}$, JEONGHOON HEO ${ }^{1,3}$ and YOUNG-HO KIM Y,3,4 $^{1,4}$ \\ ${ }^{1}$ Department of Molecular Biology and Immunology, ${ }^{2}$ Department of Internal Medicine, ${ }^{3}$ Institute for Medical Sciences, \\ ${ }^{4}$ Institute for International Healthcare Cooperation, Kosin University College of Medicine, Busan, Republic of Korea
}

Received February 7, 2013; Accepted April 25, 2013

DOI: 10.3892/or.2013.2494

\begin{abstract}
Combined treatment with a photosensitizer and iodide laser [photodynamic therapy (PDT)] has improved the outcome of various cancers. In this study, we investigated the effects of using the photosensitizer methylene blue (MB) in PDT in human lung adenocarcinoma cells. We found that MB enhances PDT-induced apoptosis in association with downregulation of anti-apoptotic proteins, reduced mitochondrial membrane potential (MMP), increased phosphorylation of the mitogen-activated protein kinase (MAPK) and the generation of reactive oxygen species (ROS). In MB-PDT-treated A549 cells, we observed PARP cleavage, procaspase-3 activation, downregulation of the anti-apoptotic proteins $\mathrm{Bcl}-2$ and $\mathrm{Mcl}-1$, and the reduction of mitochondrial membrane potential (MMP). Western blot data showed that phosphorylation of p38 was increased in MB-PDT-treated A549 cells, indicating that several signaling molecules participate in the apoptotic cascade. Our data also showed that apoptotic cell death in MB-PDT-treated cells occurred through a series of steps beginning with the photochemical generation of ROS. Demonstrating the role of ROS, pretreatment of A549 cells with the antioxidant $\mathrm{N}$-acetylcysteine (NAC) followed by MB-PDT resulted in increased cell viability and reduced proteolytic cleavage of PARP.
\end{abstract}

\section{Introduction}

Photodynamic therapy (PDT) is an emerging treatment for a variety of cancers and other diseases. In PDT the activation of a photosensitizer by a specific wavelength of light in the presence of oxygen promotes cellular damage $(1,2)$. Currently, several research groups are developing PDT technology. A variety of photosensitizers such as Photofrin ${ }^{\circledR}$, ALA and cisplatin have

Correspondence to: Dr Young-Ho Kim, Department of Molecular Biology and Immunology, Kosin University College of Medicine, 34 Amnam-dong, Seo-gu, Busan 602-703, Republic of Korea

E-mail: kimyh@kosin.ac.kr

*Contributed equally

Key words: methylene blue, photodynamic therapy, apoptosis, lung shown promising results (1-3). However, improvements in quantum efficiency, reductions in toxicity and the ability to specifically target a highly effective dose have not been fully attained with current PDT technologies.

Methylene blue (MB), a well-known dye with high light absorption at $665 \mathrm{~nm}$, is effective in PDT due to its ability to generate singlet oxygen and its proven photodynamic activity in clinical applications against several diseases (4-6). Previous studies have documented the effectiveness of MB-PDT against melanoma in cell culture, and MB-PDT has been used to efficiently treat relatively large melanoma lesions not eligible for surgery (6). In addition, some researchers have reported that MB is more toxic to leukemia cells than to normal PBMCs (7). This suggests that $\mathrm{MB}$ is more toxic in cancer cells than normal cells, a potential benefit in reducing unwanted toxicity due to PDT.

Although it has been documented that in MB-PDT the derivative of $\mathrm{MB}$ induces apoptosis in several cell lines (8), the current understanding of the mechanisms of apoptosis induced by MB-PDT is limited. Currently recognized mechanisms of apoptosis associated with MB-PDT include the induction of DNA damage, the generation of reactive oxygen species (ROS), and possibly mitochondrial damage $(9,10)$. Published data have indicated mitochondrial damage in MB-PDT-induced tumor regression because $\mathrm{MB}$ is likely to bind to the negative electrochemical environment of the mitochondrial matrix in melanoma and HeLa cells (11-13). A better understanding of the mechanisms of apoptosis induced by MB-PDT will help inform cancer therapeutic strategies.

In this study, we investigated the role of MB in PDT-induced apoptosis in human lung adenocarcinoma cells. We found that MB sensitizes A549 cells to PDT-induced apoptosis, suggesting that MB-PDT may provide an effective therapeutic strategy for lung adenocarcinoma. In addition, we found that caspase activation, downregulation of anti-apoptotic proteins, reduced mitochondrial membrane potential (MMP), activation of the mitogen-activated protein kinase (MAPK) p38, and ROS generation critically contribute to the anticancer effect of MB-PDT.

\section{Materials and methods}

Reagents. The methylene blue (MB) used for PDT was acquired from Aldrich (Milwaukee, WI, USA), and RPMI-1640 medium 
was purchased from Hyclone (Logan, UT, USA). Antibodies against PARP-1, Bcl-2, Bcl-xL, Mcl-1, and actin were purchased from Santa Cruz Biotechnology (Santa Cruz, CA, USA), and anti-phospho-JNK, anti-phospho-p38, and anti-phospho-ERK were purchased from Cell Signaling (Beverly, MA, USA). Benzyl carbonyl-Val-Ala-Asp-fluoromethyl ketone (z-VADfmk) was purchased from Biomol (Plymouth Meeting, PA, USA), 2'7'-dichlorodihydrofluorescein diacetate ( $\mathrm{H}_{2}$ DCFDA) was purchased from Molecular Probes (Eugene, OR, USA), and $\mathrm{N}$-acetylcysteine (NAC) and all other chemicals used in this study were purchased from Sigma-Aldrich (St. Louis, MO, USA).

Cell culture and chemical treatments. Human lung adenocarcinoma cells (A549 cells) were obtained from the American Type Culture Collection (Rockville, MD, USA). The A549 cells were cultured in RPMI-1640 medium supplemented with $10 \%$ heat-inactivated fetal bovine serum (FBS), penicillin $(100 \mathrm{U} / \mathrm{ml})$ and streptomycin $(100 \mathrm{U} / \mathrm{ml})$ at $37^{\circ} \mathrm{C}$ in a humidified incubator with $5 \% \mathrm{CO}_{2}$ and $95 \%$ air. When the cells were subconfluent, the medium was replaced with fresh medium and $0.1-2.0 \mu \mathrm{g} / \mathrm{ml}$ of $\mathrm{MB}$ was added to the culture medium for $1 \mathrm{~h}$. The cells were then irradiated with $650 \mathrm{~nm}$ light produced by a dye laser (Red Diode Laser) at 30-120 Joules (J).

Cellular viability assay. For the morphological evaluation of cell death, approximately $5 \times 10^{5}$ A549 cells were plated into 60-mm cell culture dishes overnight. For the trypan blue exclusion assay, trypsinized cells were pelleted and resuspended in $0.2 \mathrm{ml}$ of medium, $0.5 \mathrm{ml}$ of $0.4 \%$ trypan blue solution, and $0.3 \mathrm{ml}$ of phosphate-buffered saline solution (PBS). The samples were mixed thoroughly, incubated at room temperature for $15 \mathrm{~min}$, and examined under a light microscope. At least 300 cells were counted for each survival determination.

Western blot analysis. For western blot analyses, A549 cells were lysed with $1 \mathrm{X}$ Laemmli lysis buffer $(2.4 \mathrm{M}$ glycerol, 0.14 M Tris, pH 6.8, 0.21 M SDS, $0.3 \mathrm{mM}$ bromophenol blue) and boiled for $10 \mathrm{~min}$. Protein content was measured with the BCA Protein Assay Reagent (Pierce, Rockford, IL, USA). The samples were diluted with $1 \mathrm{X}$ Laemmli lysis buffer containing $1.28 \mathrm{M} \beta$-mercaptoethanol, and equal amounts of protein were loaded on 8-12\% SDS-polyacrylamide gels. Proteins were separated by SDS-PAGE and electrophoretically transferred to a nitrocellulose membrane. The nitrocellulose membrane was blocked with 5\% nonfat dry milk in PBS-Tween-20 (0.1\%, v/v) for $1 \mathrm{~h}$. The membrane was incubated with primary antibody (diluted according to the manufacturer's instructions) at room temperature for $1.5 \mathrm{~h}$. Horseradish peroxidase-conjugated antirabbit or anti-mouse IgG was used as the secondary antibody. Immunoreactive protein was visualized by the chemiluminescence protocol (ECL, Amersham, Arlington Heights, IL, USA). To ensure equal protein loading, each nitrocellulose membrane was stripped and reprobed with an anti-actin antibody after the experiment was completed.

DNA fragmentation and DAPI staining assay. To assess for DNA fragmentation after MB and/or PDT for $24 \mathrm{~h}, \sim 1 \times 10^{6}$ treated A549 cells were lysed for $30 \mathrm{~min}$ on ice in buffer containing $10 \mathrm{mM}$ Tris (pH 7.4), $150 \mathrm{mM} \mathrm{NaCl}, 5 \mathrm{mM}$ EDTA and $0.5 \%$ Triton X-100. Lysates were vortexed and cleared by centrifugation at $12,000 \mathrm{x} \mathrm{g}$ for $30 \mathrm{~min}$. Fragmented DNA in the supernatant was extracted with an equal volume of a mixture of neutral phenol:chloroform:isoamyl alcohol (25:24:1) and analyzed electrophoretically on $1.5 \%$ agarose gels containing $0.1 \mathrm{~g} / \mathrm{ml} \mathrm{EtBr}$. The cells were fixed on slide glass through the application of $4 \%$ paraformaldehyde for $30 \mathrm{~min}$ at room temperature. After washing with PBS, $300 \mathrm{nM}$ 4', 6'-diamidino-2-phenylindole (DAPI) was added to the fixed cells for $10 \mathrm{~min}$, after which they were examined by fluorescence microscopy. Apoptotic cells were identified by condensation and fragmentation of nuclei. All DAPI staining experiments were performed in duplicate.

Measurement of reactive oxygen species. The generation of ROS was measured by staining with 2',7'-dichlorofluorescein diacetate (DCF-DA). Briefly, A549 cells were seeded in sixwell plates $\left(1 \times 10^{5}\right.$ cells per well), allowed to attach overnight and treated with MB and/or PDT. The cells were stained with $20 \mu \mathrm{M}$ DCF-DA for $30 \mathrm{~min}$ at $37^{\circ} \mathrm{C}$ and fluorescence was detected by a fluorescence microscope.

JC-1 mitochondrial membrane potential assay. To monitor MMP, JC-1 dye was used as previously described (14). In cells with undamaged mitochondria, the aggregated dye appears as red fluorescence, whereas in cells with altered MMP that are undergoing apoptosis, the dye remains as monomers in the cytoplasm and emits diffuse green fluorescence. The red/green fluorescence ratio is dependent on MMP. After A549 cells were treated with MB and PDT, they were stained with a JC-1 MMP detection kit for 10 min and analyzed by flow cytometry. The fluorescence intensity was measured with the FACScan flow cytometer (Beckman Coulter, Inc., Hialeah, FL, USA).

Statistical analysis. All experiments were repeated three or more times. The results are represented as means \pm standard deviations (SDs). The difference between two mean values was analyzed using Student's t-test and was considered statistically significant at $\mathrm{p}<0.05$.

\section{Results}

Methylene blue promotes PDT-mediated A549 cell toxicity. To evaluate the effects of MB-PDT on cell viability, A549 cells were treated with various concentrations of MB and/or PDT (30 and $60 \mathrm{~J}$ ) for $24 \mathrm{~h}$ and a trypan blue assay was performed. As shown in Fig. 1, while MB alone had little effect on cell viability, MB treatment followed by PDT significantly decreased cell viability as determined by trypan blue exclusion (Fig. 1A) and DAPI staining (Fig. 1B). These results suggest that PDT enhances the toxicity of MB in A549 cells.

Methylene blue promotes PDT-induced apoptosis by caspase activation. To address the significance of caspase activation in MB-PDT-induced apoptosis, we examined caspase activity after MB-PDT. Treatment of A549 cells with various concentrations of MB and PDT resulted in a dramatic increase in the cleavage of PARP, a caspase substrate, and in the cleavage of procaspase-3 (Fig. 2A) in a time-dependent manner (Fig. 2B). 
A

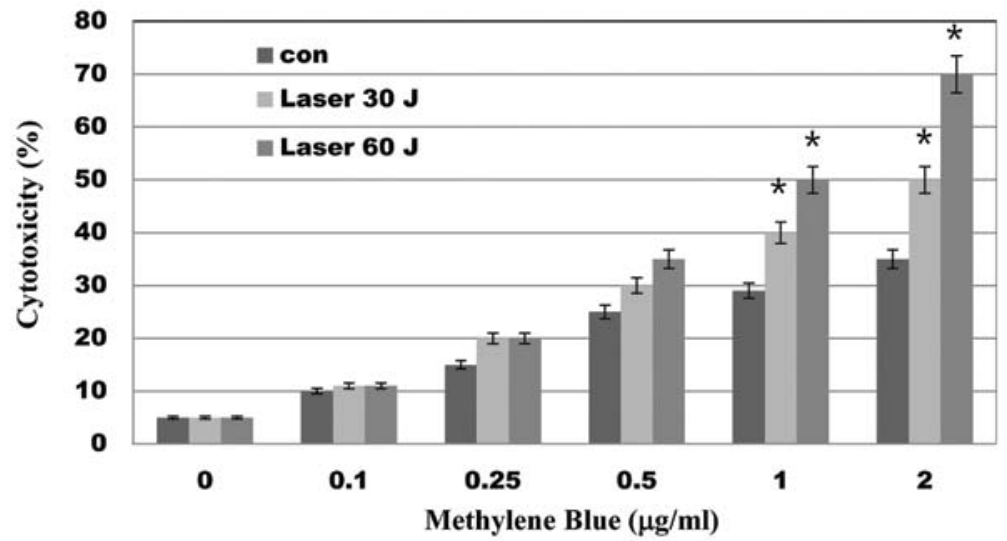

B

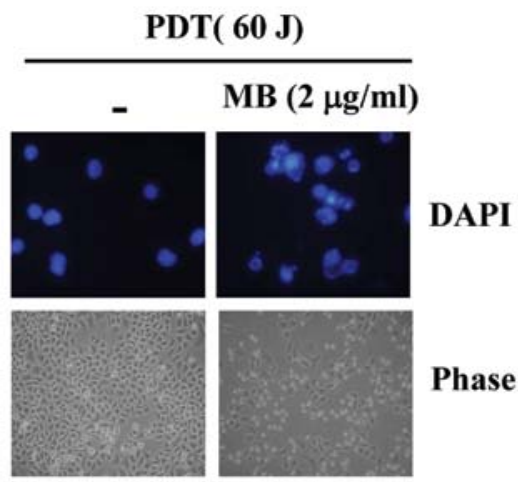

Figure 1. Cytotoxicity of MB and PDT in A549 cells. (A) A549 cells were treated with the indicated concentrations of MB followed by laser irradiation (30 and $60 \mathrm{~J}$ ). A trypan blue assay was then used to measure cell viability. " $\mathrm{p}<0.05$ compared with MB-treated cells (B) A549 cells after DAPI staining. A549 cells were fixed, washed with PBS, stained with DAPI and examined by fluorescence microscopy. Data are expressed as the mean \pm SD of three independent experiments.

A

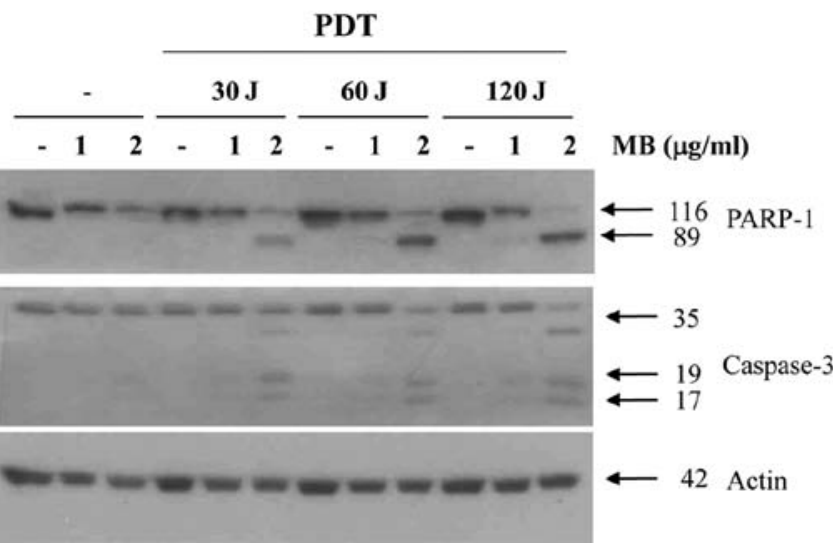

B

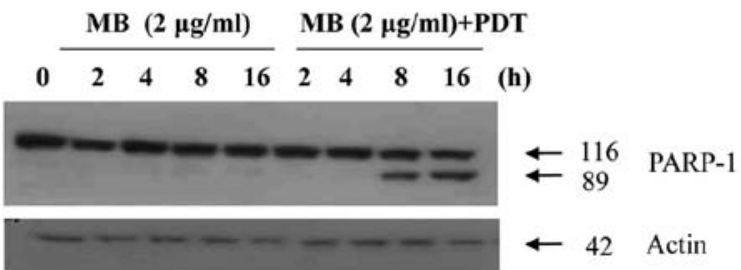

C

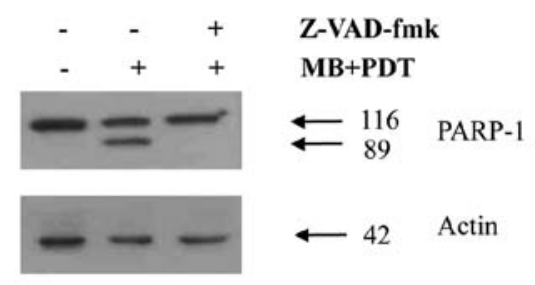

D
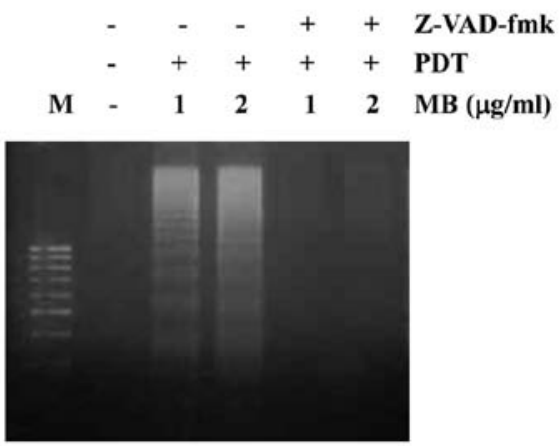

Figure 2. Effects of MB-PDT on caspase activation in A549 cells. (A) A549 cells were treated with the indicated concentrations of MB before PDT and incubated for $24 \mathrm{~h}$. Equal amounts of cell lysates $(20 \mu \mathrm{g})$ were subjected to electrophoresis and analyzed by western blotting for PARP, procaspase-3 and actin. (B) A549 cells were treated with MB $(2 \mu \mathrm{g} / \mathrm{ml})$ or PDT (60 J) or both for various time periods. Equal amounts of cell lysates $(20 \mu \mathrm{g})$ were subjected to electrophoresis and analyzed by western blotting for PARP and actin. (C) A549 cells were pre-incubated with $25 \mu \mathrm{M} \mathrm{z}$-VAD-fmk for $1 \mathrm{~h}$ before combined treatment with MB and PDT for $24 \mathrm{~h}$. Equal amounts of cell lysates $(20 \mu \mathrm{g})$ were subjected to electrophoresis and analyzed by western blotting for PARP and actin. (D) A549 cells were pre-incubated with $25 \mu \mathrm{M} \mathrm{z}$-VAD-fmk for $1 \mathrm{~h}$ before combined treatment with MB and PDT for $24 \mathrm{~h}$. Fragmented DNA was extracted and analyzed on a $2 \%$ agarose gel. 
$\mathbf{A}$

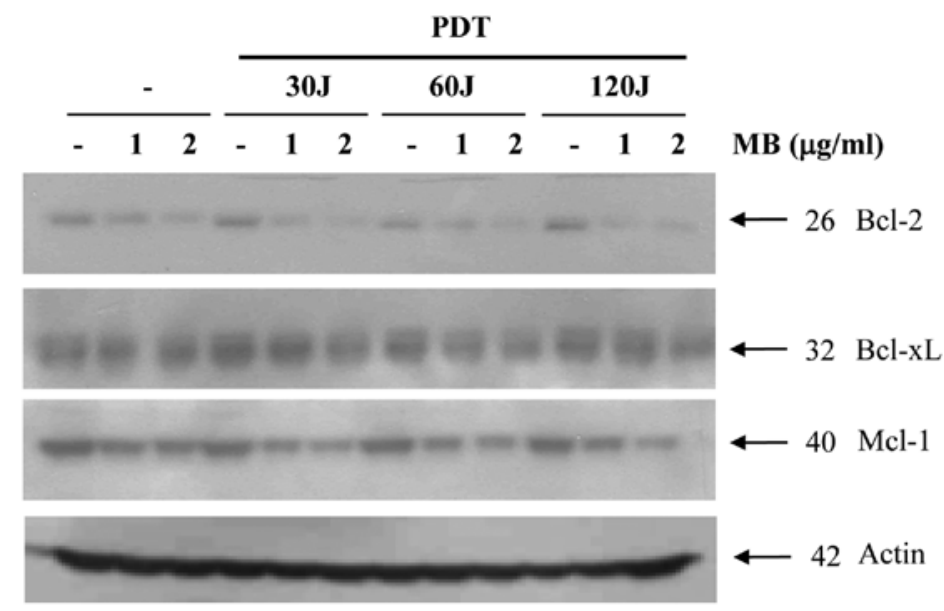

B

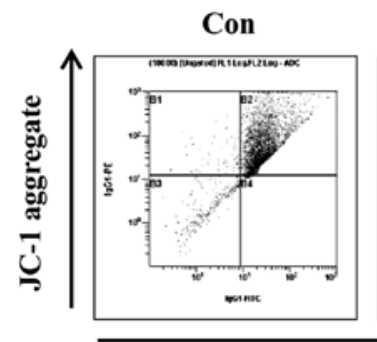

MB $2 \mu \mathrm{g} / \mathrm{ml}$

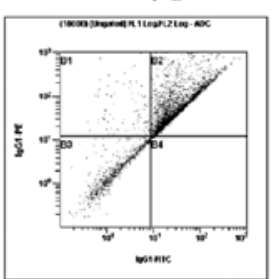

MB $1 \mu \mathrm{g} / \mathrm{ml}$ $+\operatorname{PDT}(60 \mathrm{~J})$

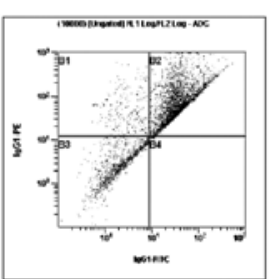

MB $2 \mu \mathrm{g} / \mathrm{ml}$

+ PDT (60 J)

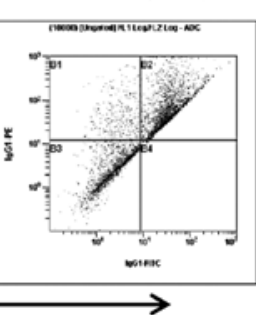

JC-1 monomer

Figure 3. Effects of MB and PDT on anti-apoptotic protein expression and mitochondrial function in A549 cells. (A) The levels of apoptosis-related protein expression was analyzed after treatment with MB and/or PDT in A549 cells. Equal amounts of whole cell lysate $(20 \mu \mathrm{g})$ were subjected to electrophoresis and analyzed by western blotting for Bcl-2, Bcl-xL and Mcl-1. Western blotting of actin served as an internal control. (B) Loss of MMP following treatment with MB and/or PDT. A549 cells were treated with MB or PDT or both for $24 \mathrm{~h}$, then incubated with JC-1 for $1 \mathrm{~h}$. Fluorescence was measured by flow cytometry.

In order to confirm that the activation of caspases is a key step in MB-PDT-induced apoptosis, the A549 cells were pretreated with z-VAD-fmk $(25 \mu \mathrm{M})$, a cell-permeable caspase inhibitor, followed by MB-PDT for $24 \mathrm{~h}$. As shown in Fig. 2C, MB-PDT-induced apoptosis was prevented by pretreatment with z-VAD-fmk, as indicated by the reduced PARP cleavage. We also found that $\mathrm{z}$-VAD-fmk prevented the dose-dependent increase in the accumulation of apoptotic DNA after treatment with MB-PDT (Fig. 2D). These results suggest that MB-PDTinduced cell death is associated with caspase activation.

$M B$ and PDT induce downregulation of anti-apoptotic proteins and loss of mitochondrial membrane potential in A549 cells. We further examined whether MB-PDT-induced apoptosis is associated with the modulation of apoptosis regulatory proteins. As shown in Fig. 3A, exposure of A549 cells to MB and PDT led to a slight decrease in Bcl-xL. However, levels of Bcl-2 and Mcl-1 in A549 cells were markedly reduced by MB and PDT in a dose-dependent manner. We assessed MMP in order to determine the role of mitochondrial damage in MB-PDT-induced apoptosis of A549 cells. As shown in Fig. 3B, we found that exposure of A549 cells to MB and PDT significantly reduced MMP in a dose-dependent manner. The proportion of cells with a loss of MMP substantially increased with MB treatment (1 and $2 \mu \mathrm{g} / \mathrm{ml})$ plus PDT $(60 \mathrm{~J})$.

Activation of p38 signaling plays an important role in MB-induced photosensitization in A549 cells. In order to investigate whether a MAPK signaling pathway was involved in cell death in A549 cells treated with MB-PDT, we examined the phosphorylation of p38, JNK and ERK in A549 cells after MB and/or PDT. As shown in Fig. 4A, p38 activity was increased slightly at $2 \mathrm{~h}$ after MB application $(2 \mu \mathrm{g} / \mathrm{ml})$ and the increased p38 activity was sustained after $8 \mathrm{~h}$ of treatment with MB alone, whereas a much stronger and prolonged activation of $\mathrm{p} 38$ was observed after combined treatment with MB and PDT. To further confirm the involvement of the p38 signaling pathway in MB-PDT-induced apoptosis, we applied specific inhibitors of JNK (SP600125), p38 (SB203589), and ERK (PD98059). Pretreatment of A549 cells with the p38 inhibitor SB203589 before MB-PDT increased cell viability (Fig. 4B) and reduced proteolytic cleavage of PARP (Fig. 4C). Taken together, these results suggest that the prolonged activation of the MAPK p38 pathway plays an important role in MB-induced photosensitization.

$M B$ potentiates PDT-induced ROS generation, which is attenuated by the addition of antioxidants to A549 cells. ROS are byproducts of the normal metabolism of oxygen, and they are generated by various environmental stresses such as drugs, UV light and heat shock. ROS play an important role in apoptosis under both physiologic and pathologic conditions $(15,16)$. Therefore, we examined whether ROS generation was involved in MB-induced photosensitization of A549 cells by measuring the intracellular hydrogen peroxide level in A549 cells after MB-PDT. As shown in Fig. 5A, the combination of MB and PDT markedly increased intracellular hydrogen peroxide levels in A549 cells. We next investigated whether ROS generation 
$\mathbf{A}$
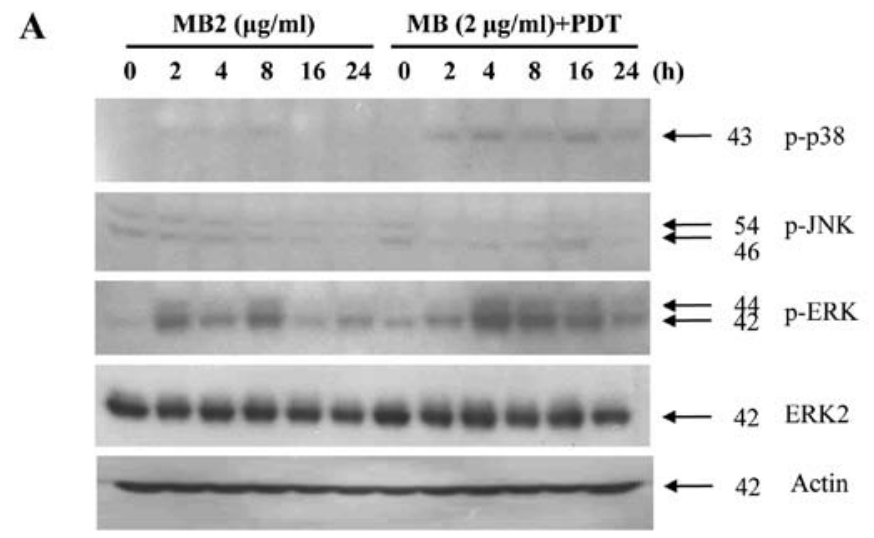

B

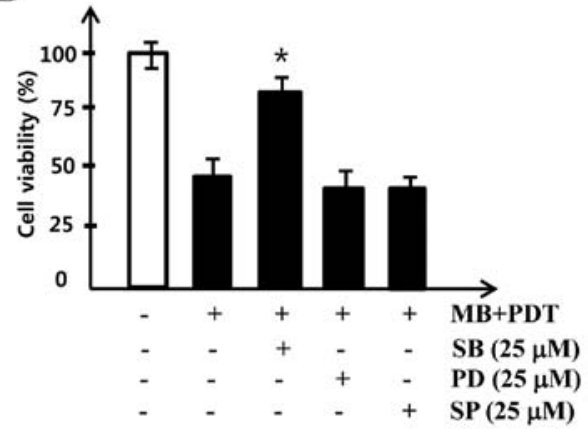

C

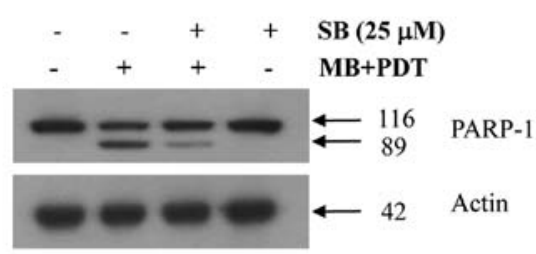

Figure 4. Effects of MB and PDT on the p38 MAPK signaling pathway. (A) A549 cells were treated with MB ( $2 \mu \mathrm{g} / \mathrm{ml})$ and/or PDT (60J) for various time periods. Levels of phosphorylated p38, JNK and ERK were detected by western blotting using specific p-p38, p-JNK and p-ERK antibodies. (B) A549 cells were pretreated with specific inhibitors of JNK (SP600125), p38 (SB203589) and ERK (PD98059) at the indicated concentration and further treated with $2 \mu \mathrm{g} / \mathrm{ml}$ of MB and PDT for $24 \mathrm{~h}$. Cell viability was then assessed by trypan blue assay. " $\mathrm{p}<0.05$ compared with MB+PDT treated cells (C) A549 cells were pretreated with SB203589 at the indicated concentration and further treated with $2 \mu \mathrm{g} / \mathrm{ml}$ of MB and PDT for $24 \mathrm{~h}$. Equal amounts of whole cell lysates were subjected to electrophoresis and analyzed by western blotting for PARP, and actin served as a loading control.

A

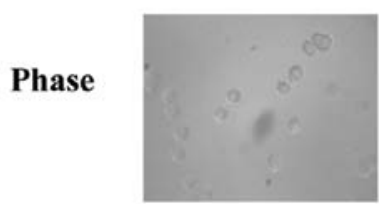

DCFDA

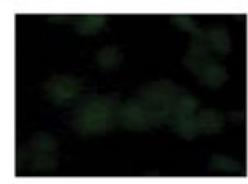

B

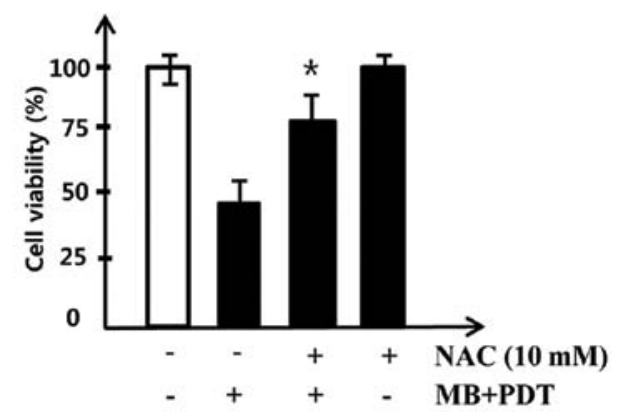

MB+PDT
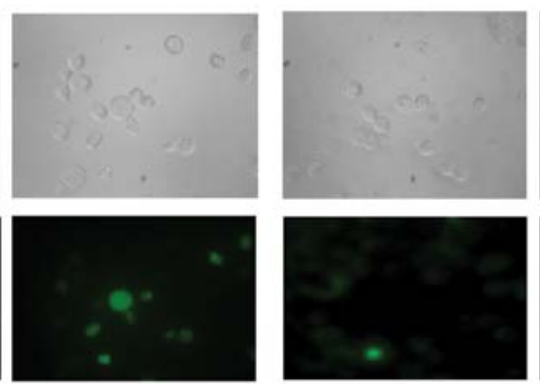

C
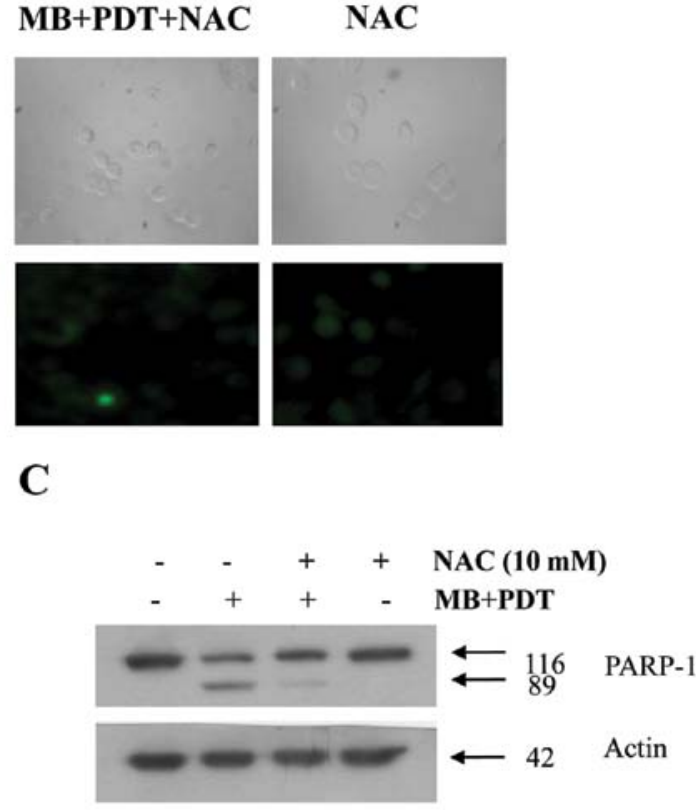

Figure 5. Effects of MB and PDT on ROS generation in A549 cells. (A) A549 cells were pre-incubated in the absence or presence of MB $(1 \mu \mathrm{g} / \mathrm{ml})$ for $1 \mathrm{~h}$ and subsequently treated with or without a PDT $(60 \mathrm{~J})$ for $24 \mathrm{~h}$. Cells were then incubated with $20 \mu \mathrm{M}$ DCFDA at $37^{\circ} \mathrm{C}$ for 30 min and ROS generation was measured using a flow cytometer or a fluorescence microscope. (B) A549 cells were pre-incubated in the presence or absence of NAC (10 mM) for $1 \mathrm{~h}$ and subsequently treated with or without MB plus an iodide laser for $24 \mathrm{~h}$. Cell viability was then assessed by a trypan blue assay. ${ }^{*} \mathrm{p}<0.05$ compared with MB+PDT-treated cells. (C) A549 cells were pre-incubated in the presence or absence of NAC (10 mM) and subsequently treated with MB $(1 \mu \mathrm{g} / \mathrm{ml})$ and a PDT $(60 \mathrm{~J})$ for $24 \mathrm{~h}$. Equal amounts of whole cell lysates $(20 \mu \mathrm{g})$ were subjected to electrophoresis and analyzed by western blotting for PARP, and actin served as a loading control. 
was directly associated with MB-PDT-induced apoptosis Pretreatment with NAC, a well-known antioxidant, markedly increased cell viability after MB-PDT (Fig. 5B). Moreover, apoptosis induced by MB-PDT was markedly attenuated by pretreatment with NAC (Fig. 5C). Taken together, these results indicate that MB-induced photosensitization and MB-PDTinduced apoptosis are mediated by the generation of ROS.

\section{Discussion}

Although PDT is a commonly applied cancer therapy, its efficacy is limited by injury to healthy tissue, varying tumor sensitivity and various other side effects. Therefore, novel therapeutic strategies are needed to selectively induce the death of cancer cells while sparing normal cells. Recently, many attempts to improve the therapeutic effects of PDT have been reported (17) and several photosensitizers such as porfimer sodium (Photofrin), ALA and cisplatin have been used to enhance tumor cell death in PDT $(18,19)$. In this study, we found that MB effectively sensitizes A549 human lung adenocarcinoma cells to PDT-induced apoptosis through caspase activation, downregulation of anti-apoptotic proteins, reduced MMP, activation of $\mathrm{p} 38$ signaling pathways and increased ROS.

MB is already approved for systemic administration by intravenous injection for clinical use in patients with other diseases. It has various biological applications, it is used as a staining dye for parathyroid tissue (20), an antifungal agent in goldfish, and an antimalarial agent (21). In the present study, we showed that compared with MB or PDT alone, the combination of MB and PDT resulted in significantly enhanced A549 cell death (Fig. 1). This enhancement of PDT-induced apoptosis by MB was dependent on caspase activation, since z-VAD-fmk, a caspase inhibitor, reduced the cell death induced by MB-PDT (Fig. 2).

Mitochondria play an important role in apoptotic pathways that result from a variety of intracellular events including the release of caspase activators, changes in MMP, ROS generation, and changes in the Bcl-2 family of proteins (22). In the current study, loss of MMP was observed in A549 cells co-treated with MB and PDT (Fig. 3). Levels of Bcl-2 in A549 cells were also markedly decreased by MB-PDT. Taken together, these results suggest that the mitochondrial pathway is involved in the enhancement of PDT-induced apoptosis by MB.

The activation of MAPK pathways plays an essential role in apoptosis induced by many cellular stresses. The p38 MAPK is activated by ROS in many cells treated with radiation, anticancer drugs, and chemopreventive agents (23). In our study, MB-PDT-treated A549 cells showed remarkably activated p38, but not JNK or ERK MAPK (Fig. 4). Pretreatment of A549 cells with the p38 inhibitor SB203589 prevented MB-PDTinduced apoptosis. These results suggest that activation of the p38 MAPK pathway contributes to MB-PDT-induced apoptosis in A549 cells.

ROS are generated by many environmental stresses (e.g., UV light and heat shock), and they are produced as a normal product of cellular metabolism (e.g., phagocytosis). ROS play an important role in apoptosis induction under both physiologic and pathologic conditions (16). In the current study, we show that co-treatment with MB and PDT induced ROS generation in A549 cells. Furthermore, antioxidant (NAC) pretreatment attenuated ROS generation and MB-PDT-induced apoptosis (Fig. 4), suggesting that the elevation of ROS levels by combined treatment with MB and PDT plays an important role in enhancing the apoptotic susceptibility of A549 cells.

In conclusion, the present study shows that MB enhances PDT-induced apoptosis in human lung adenocarcinoma cells via caspase activation, reductions in anti-apoptotic protein levels, loss of MMP, activation of the p38 MAPK signaling pathway and ROS generation. Therefore, a combined regimen of MB and PDT may offer a better therapeutic strategy to enhance photosensitivity in tumor cells.

\section{Acknowledgements}

This work was supported by Basic Science Research Program through the NRF funded by the Ministry of Education, Science and Technology (2011-0004206) and a grant from Kosin University College of Medicine (2011) and a grant from Institute for Medical Sciences (2011).

\section{References}

1. Dougherty TJ, Gomer CJ, Henderson BW, Jori G, Kessel D, Korbelik M, Moan J and Peng Q: Photodynamic therapy. J Natl Cancer Inst 90: 889-905, 1998.

2. Dolmans DE, Fukumura D and Jain RK: Photodynamic therapy for cancer. Nat Rev Cancer 3: 380-387, 2003.

3. Sharman WM, Allen CM and van Lier JE: Photodynamic therapeutics: basic principles and clinical applications. Drug Discov Today 4: 507-517, 1999.

4. Bisland SK, Chien C, Wilson BC and Burch S: Pre-clinical in vitro and in vivo studies to examine the potential use of photodynamic therapy in the treatment of osteomyelitis. Photochem Photobiol Sci 5: 31-38, 2006.

5. Tardivo JP, Del Giglio A, Paschoal LH and Baptista MS: New photodynamic therapy protocol to treat AIDS-related Kaposi's sarcoma. Photomed Laser Surg 24: 528-531, 2006.

6. Wagner M, Suarez ER, Theodoro TR, Machado Filho CD Gama MF, Tardivo JP, Paschoal FM and Pinhal MA: Methylene blue photodynamic therapy in malignant melanoma decreases expression of proliferating cell nuclear antigen and heparanases. Clin Exp Dermatol 37: 527-533, 2012.

7. Kirszberg C, Rumjanek VM and Capella MA: Methylene blue is more toxic to erythroleukemic cells than to normal peripheral blood mononuclear cells: a possible use in chemotherapy. Cancer Chemother Pharmacol 56: 659-665, 2005.

8. Ball DJ, Luo Y, Kessel D, Griffiths J, Brown SB and Vernon DI: The induction of apoptosis by a positively charged methylene blue derivative. J Photochem Photobiol B 42: 159-163, 1998.

9. Noodt BB, Rodal GH, Wainwright M, Peng Q, Horobin R, Nesland JM and Berg K: Apoptosis induction by different pathways with methylene blue derivative and light from mitochondrial sites in V79 cells. Int J Cancer 75: 941-948, 1988.

10. Rodrigues T, de França LP, Kawai C, de Faria PA, Mugnol KC, Braga FM, Tersariol IL, Smaili SS and Nantes IL: Protective role of mitochondrial unsaturated lipids on the preservation of the apoptotic ability of cytochrome $\mathrm{C}$ exposed to singlet oxygen. $\mathrm{J}$ Biol Chem 282: 25577-25587, 2007.

11. Gabrielli D, Belisle E, Severino D, Kowaltowski AJ and Baptista MS: Binding, aggregation and photochemical properties of methylene blue in mitochondrial suspensions. Photochem Photobiol 79: 227-232, 2004.

12. Chen Y, Zheng W, Li Y, Zhong J, Ji J and Shen P: Apoptosis induced by methylene-blue-mediated photodynamic therapy in melanomas and the involvement of mitochondrial dysfunction revealed by proteomics. Cancer Sci 99: 2019-2027, 2008.

13. Lu Y, Jiao R, Chen X, Zhong J, Ji J and Shen P: Methylene bluemediated photodynamic therapy induces mitochondria-dependent apoptosis in HeLa cell. J Cell Biochem 105: 1451-1460, 2008.

14. Kim MJ, Lee TH, Kim SH, Choi YJ, Heo J and Kim YH: Triptolide inactivates Akt and induces caspase-dependent death in cervical cancer cells via the mitochondrial pathway. Int J Oncol 37: 1177-1185, 2010. 
15. Szatrowski TP and Nathan CF: Production of large amounts of hydrogen peroxide by human tumor cells. Cancer Res 51: 794-798, 1991.

16. Simon HU, Haj-Yehia A and Levi-Schaffer F: Role of reactive oxygen species (ROS) in apoptosis induction. Apoptosis 5 415-418, 2000.

17. Firczuk M, Winiarska M, Szokalska A, Jodlowska M, Swiech M, Bojarczuk K, Salwa P and Nowis D: Approaches to improve photodynamic therapy of cancer. Front Biosci 16: 208-224, 2011.

18. Nahabedian MY, Cohen RA, Contino MF, Terem TM, Wright WH, Berns MW and Wile AG: Combination cytotoxic chemotherapy with cisplatin or doxorubicin and photodynamic therapy in murine tumors. J Natl Cancer Inst 80: 739-743, 1988.

19. Peng Q, Warloe T, Moan J, Godal A, Apricena F, Giercksky KE and Nesland JM: Antitumor effect of 5-aminolevulinic acidmediated photodynamic therapy can be enhanced by the use of a low dose of photofrin in human tumor xenografts. Cancer Res 61: 5824-5832, 2001.
20. Sherlock DJ and Holl-Allen RT: Intravital methylene blue staining of parathyroid glands and tumours. Ann R Coll Surg Engl 66: 396-398, 1984

21. Meissner PE, Mandi G, Coulibaly B, Witte S, Tapsoba T, Mansmann U, Rengelshausen J, Schiek W, Jahn A, Walter-Sack I, Mikus G, Burhenne J, Riedel KD, Schirmer RH, Kouyaté B and Müller O: Methylene blue for malaria in Africa: results from a dose-finding study in combination with chloroquine. Malar J 5: 84, 2006.

22. Yang ES, Choi MJ, Kim JH, Choi KS and Kwon TK: Combination of withaferin A and X-ray irradiation enhances apoptosis in U937 cells. Toxicol In Vitro 25: 1803-1810, 2011.

23. Chen YR and Tan TH: The c-Jun N-terminal kinase pathway and apoptotic signaling. Int J Oncol 16: 651-662, 2000 